\title{
Comparison \& Measurement of Energy Efficiency of Micro and Macro Base Stations in Nepal Using Regression Model
}

\author{
Madhu Sudan Dahal*, Jagan Nath Shrestha and Shree Raj Shakya \\ Department of Mechanical Engineering, Pulchowk Campus, Institute of \\ Engineering, Tribhuvan University, Lalitpur, Nepal \\ E-mail:msdahal@ioe.edu.np; shresthajn@gmail.com; \\ shreerajshakya@ioe.edu.np \\ ${ }^{*}$ Corresponding Author
}

Received 30 November 2017; Accepted 14 March 2018;

Publication 06 April 2018

\begin{abstract}
Power consumption of cellular communication is growing at a very high rate due to the mass deployment of Base Stations (BSs). When traffic increases, the power consumption also increases, however this scenario differs in micro and macro BSs. Therefore intelligent energy management system as per traffic generated is very essential. The available models have not considered the impact of traffic load on energy consumption. These variations are analysed through regression models among power consumption and traffic load. Linear models have been proposed based on the measurements performed for ten consecutive days on three micro and three macro BSs. The results revealed that the proposed linear models fit better for macro BS than for micro BS. Energy consumption is observed to change along with the traffic load during high traffic, but during low traffic, energy consumption does not change. A macro BS is found to be more energy efficient than a micro BS due to its higher coverage range. On the contrary, a macro BS consumes about double power than that of a micro BS. Hence, micro BSs are suitable for areas with higher concentration of users where high data rates are required, whereas macro BSs are suitable to provide coverage only.
\end{abstract}

Journal of Green Engineering, Vol. 7_4, 505-526.

doi: 10.13052/jge1904-4720.743

This is an Open Access publication. (c) 2018 the Author(s). All rights reserved. 
Keywords: Energy efficiency, power consumption, modelling, base station, coverage, cellular communication.

\section{List of Notations and Abbreviations}

BSs: Base stations; GDP: Gross Domestic Product; BSC: Base Station Controller; EARTH: Energy Aware Radio and neTworking technology; BS: base transceiver station; TRX: Transmitter; UMTS: Universal mobile telecommunication system; LTE: Long Term Evaluation; PA: Power Amplifier; AC: Alternate current; DC: Direct current; RF: Radio frequency; MS: Mobile Station; GSM: Global system for mobile communication; 3GPP: 3rd Generation partnership project.

\section{Introduction}

The arena of telecommunication has been expanding at an alarming rate over the last decade and has become a very crucial part of people's daily life. It is clearly reflected in the fact that the tele-density in Nepal has surged to $141.83 \%$ in 2017 [1]. The annual gross domestic product (GDP) per capita of Nepal was $730 \$$ in the year 2016, and for every $10 \%$ increase in broadband penetration, GDP increases for $1.38 \%$ [2]. The growing interest in quality services in cellular communications has resulted in increased number of installed BSs in Nepal.

In Nepal, there is only a meagre supply of electricity with more than 14 hours of load shedding per day due to which the country is severely facing energy crisis [3]. Hence, the main challenge is to provide reliable and cost effective power supply solution for powering the BSs in urban, sub urban and rural areas [4-6]. So the first prerequisite is to model the power consumption of the entire wireless access network. Within the cellular communication, $10 \%$ of energy is consumed by the user terminals, while the remaining $90 \%$ is consumed by the base stations [7]. Hence, increasing energy efficiency of the cellular networks can save significant amount of energy [8]. Energy Aware Radio and Networking Technologies (EARTH) project aims at enabling greener communication by defining new network architectures, improved deployment strategies and resource management and finally increasing efficiency of access networks $[9,10]$. A dynamic power consumption depends on the traffic load adds to the static part, which results in variation on the total power consumption [11].

The contribution of this research can be listed as follows:

- A power consumption model for both macro and micro base stations has been proposed showing the difference in the dynamic and static part of the power consumption. 
- Energy efficiency of micro and macro BSs installed in urban and rural areas are compared as per traffic load to increase energy efficiency.

- Finally, a regression model is developed by power and traffic measurement on actual micro and macro base stations.

To the best of our knowledge, this study analyses regression models and energy efficiency expressing interdependence between instantaneous BSs power consumption and traffic load for micro and macro BSs.

\section{Related Works}

The growing interest towards power consumption in the field of cellular communication is tremendously increasing the issue on reducing power consumption in a fourth generation heterogeneous network by using the concept of cell zooming and sleep mode mechanism [12]. The EARTH project has promoted energy efficiency for cellular communication and proposes new network architectures and resource management [9]. The energy efficiency of $5 \mathrm{G}$ network is investigated based on Landauer principle and simulation results reveal that more than $50 \%$ of the energy is consumed by the computation power at 5G small cell [13]. The energy efficiency of small cellular network has targeted on the optimization of transmit power at base stations. The sleeping mode of base stations has been considered to improve energy efficiency in which transmitters are shut down to save energy [14]. The computation power of base stations will become larger than the transmit power of base station against lower transmit power for micro base stations [15]. A power consumption model developed for macro cell and micro cell of a BS validated by temporal power measurements on actual base stations is presented in [16] but it did not consider the impact of traffic. In [17], a power consumption model as a function of the traffic is developed for a macro cell base station based on measurements and this model helps to develop an energy-efficient wireless access networks. In [18], the authors affirm that the micro cells are potentially more energy efficient than conventional cells due to high path loss exponent. A power consumption model as a function of the traffic load in $3 \mathrm{G}$ Universal Mobile Telecommunication System (UMTS) network is proposed in [19]. In [11], the authors evaluated the energy consumption of 4G networks by simulation for the impact of green communication during the period of 2010-2020.

In [12], the authors focused on reducing power consumption in a fourth generation $(4 \mathrm{G})$ heterogeneous network formed from different base stations 
types, by extending the concept of cell zooming and sleep mode mechanism to define a novel algorithm that can be deployed on a control server. In [7], the authors focused on monitoring energy consumption with traffic load with experimental data collected, showing how the BSs could save energy by using Monte Carlo Simulation. The optimization of energy consumption of BSs, energy optimization of the site and energy optimization of the network and radio frequency connection is presented in [20]. The concept of cell zooming and the mechanism to reduce overall energy consumption of the network has been explained in [21].

\section{Methodology}

The measurement involved six BSs located at various areas of Nepal so as to develop interrelationship between traffic load and power consumption of heterogeneous BSs. Such dissemination enables higher and reliable level of result confidentiality in measuring the versatile BSs traffic/power profiles from larger number of different and geographically scattered locations. Since it was in testing phase, Long Term Evolution (LTE) technology is not considered in the analysis. Nevertheless, due to the average lifetime of BSs estimated for 10 years, the result obtained for GSM and UMTS BSs are of significant practical importance [22].

The technical characteristics of all the analyzed BSs are shown in Table 1. The analyzed BSs are of micro and macro types. Three of six analyzed BSs are micro GSM BSs, while the remaining thee macro BSs also work in frequency bands of $1800 \mathrm{MHz}$. In case of macro 1800 second generation Time Division Multiple Access (2G-TDMA) BSs, the transmit (TRX) power is $60 \mathrm{~W}$, while micro 2G-TDMA BSs equals to $13 \mathrm{~W}$. Micro and macro BSs located at different locations such as urban and rural areas were analyzed. Rural areas are characterized as areas with large number of cellular users, while urban areas represent business areas, where large number of cellular users work during working hours in a day $[23,24]$.

In this research, three micro and macro base stations with operating frequency $1800 \mathrm{MHz}$ and located in rural and urban areas were taken. The real time traffic was measured from the server for ten consecutive days on hourly basis of each base station. Since cellular networks are rarely fully loaded [25], it is important to model the power consumption as per traffic, which will help to increase energy efficiency of cellular networks. 


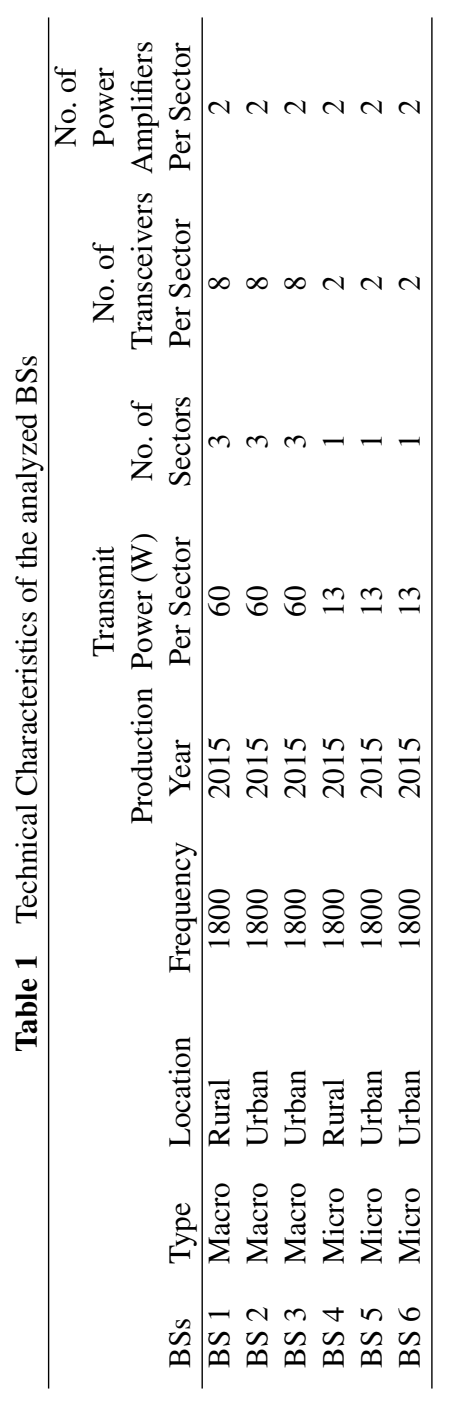




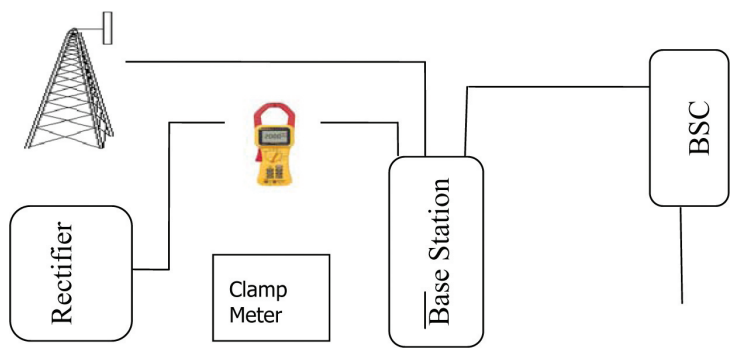

Figure 1 Measurement Setup.

\subsection{Measurements}

The experiment was conducted on the BSs room and core room in Kathmandu, Nepal. The clamp meter and the multi meter were connected to the power cable of the BS as shown in Figure 1. Power consumption is the product of current and potential difference. Power consumption of heterogeneous BSs was measured on BSs sites, while traffic load has been derived from the BSs server. Current of the analyzed BSs were measured continuously on site by clamp meter. The measured current was saved every hour, which resulted in total 240 samples for each BS for ten days continuously.

\section{Results and Discussion}

\subsection{Energy Consumption \& Traffic Load}

To understand the characteristics of energy consumption, the amount of traffic handled by the heterogeneous BSs must be considered. The relationship between traffic statistics and power consumption was studied for a period of 10 consecutive days (June 1-10, 2016). Typical traffic behaviour and power consumption of ten days is presented in Figures $2-7$, where the power consumption is related to the traffic load. The horizontal axis shows the time period, while the ordinate axis shows the traffic and power consumption. Regression analysis was done to understand the behaviour of energy consumption as a function of load of traffic statistics.

It was found that the energy consumption is directly related to the traffic load. Table 2 shows the measured minimum and maximum values of traffic transmission and power consumption for each macro and micro BSs during the study period. The average power consumption of micro BSs is nearly half the lower in comparison with that of macro BSs. Correspondingly, the average traffic transmission of micro BSs is significantly lower. The voice traffic is 
Comparison \& Measurement of Energy Efficiency 511

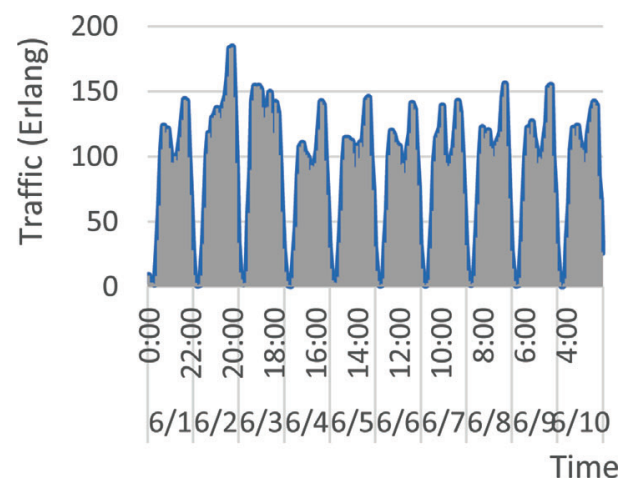

Figure 2 Traffic Volume of Macro BS1.

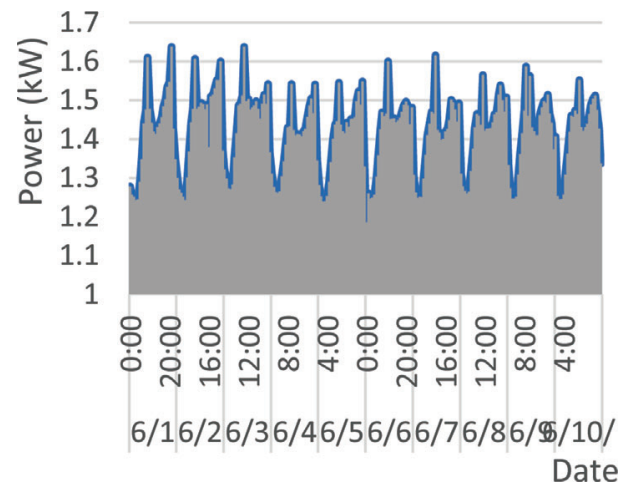

Figure 3 Power consumption of Macro BS1.

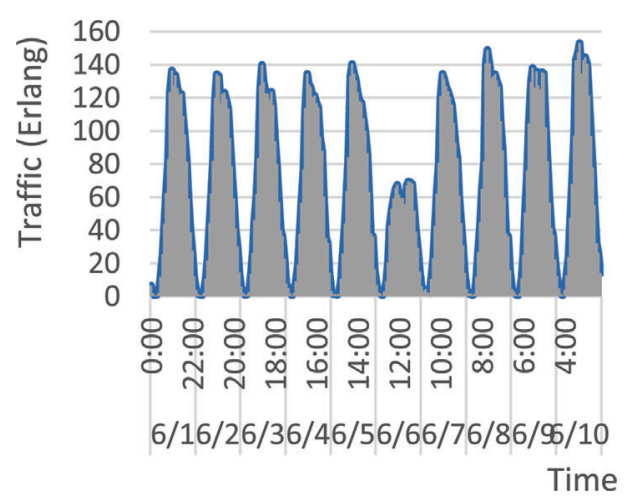

Figure 4 Traffic Volume of BS 2 Macro BS. 
512 Madhu Sudan Dahal et al.

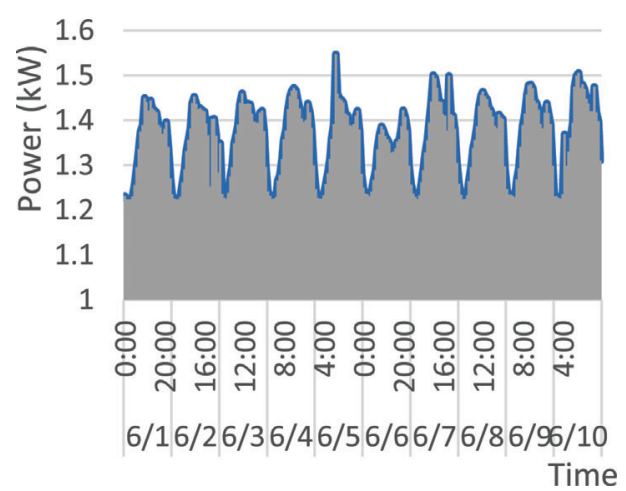

Figure 5 Power consumption of Macro BS2.

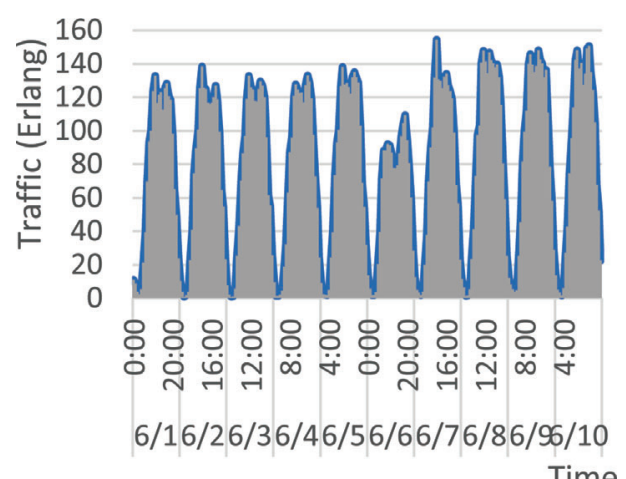

Figure 6 Traffic Volume of Macro BS3.

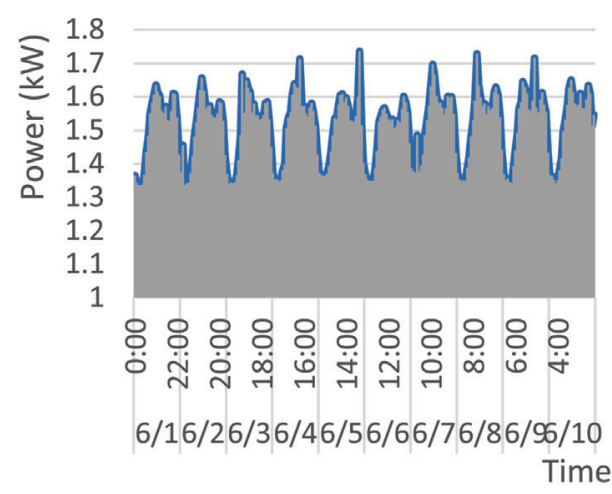

Figure 7 Power consumption of Macro BS3. 
Table 2 Maximum and minimum measured values of each BS

\begin{tabular}{lcccc}
\hline & $\begin{array}{c}\text { Maximum } \\
\text { Traffic } \\
\text { (Erlang) }\end{array}$ & $\begin{array}{c}\text { Minimum } \\
\text { Traffic } \\
\text { (Erlang) }\end{array}$ & $\begin{array}{c}\text { Maximum Power } \\
\text { Consumption (kW) }\end{array}$ & $\begin{array}{c}\text { Minimum Power } \\
\text { Consumption (kW) }\end{array}$ \\
\hline Macro BS 1 & 184 & 0.904 & 1.637 & 1.185 \\
Macro BS 2 & 153.129 & 0.281 & 1.547 & 1.224 \\
Macro BS 3 & 154.483 & 0.778 & 1.736 & 1.248 \\
Micro BS 4 & 56.036 & 0.11 & 0.482 & 0.202 \\
Micro BS 5 & 11.883 & 0.1 & 0.354 & 0.209 \\
Micro BS 6 & 5.568 & 0.12 & 0.313 & 0.209 \\
\hline
\end{tabular}

characterized by very low traffic at night, with an increase in the morning and few peaks corresponding to afternoon and evening. This change is certainly due to the difference in behaviour of subscribers.

The instantaneous power consumption of macro BSs and micro BSs are presented in Figures 3, $5 \& 7$ and Figures 9, $11 \& 13$ respectively. An important feature to be considered in traffic statistics is social behaviour and activities of the users. Similar graph patterns are depicted in Figures 2, $4 \& 6$ for macro and $8,10 \& 12$ for micro BSs. Data analysis shows the difference in energy consumption between the periods of minimum and maximum traffic is about $1.224 \mathrm{kWh}$ to $1.736 \mathrm{kWh}$ for macro and $0.202 \mathrm{kWh}$ to 0.482 for micro BS.

By comparing the results presented in Figures 2-7 (Macro BSs) and Figures 8-13 (Micro BSs), it can be generalized that there is a direct relationship between traffic load and instantaneous power consumption. Apparently, when the communication activities of users are low (00:00 to 6:00 hrs.), instantaneous power consumption of both micro and macro BSs located in

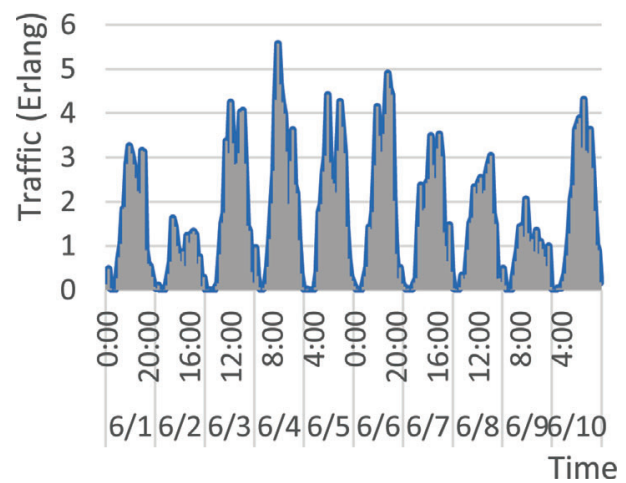

Figure 8 Traffic Volume of Micro BS4. 
514 Madhu Sudan Dahal et al.

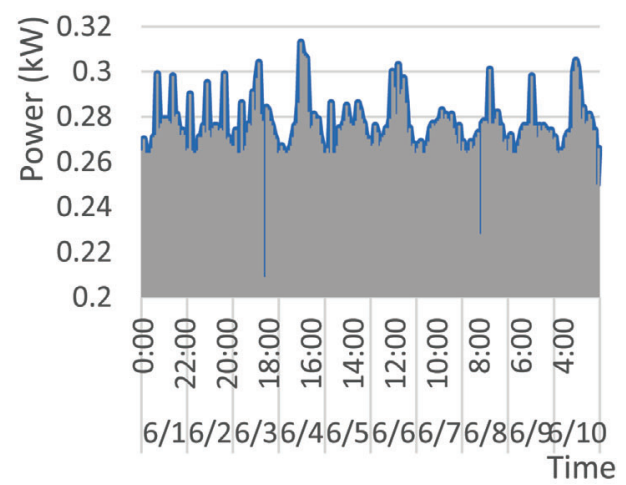

Figure 9 Power consumption of Micro BS4.

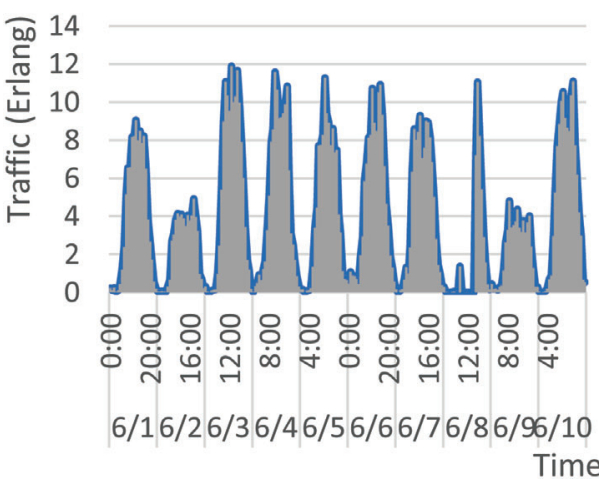

Figure 10 Traffic Volume of Micro BS5.

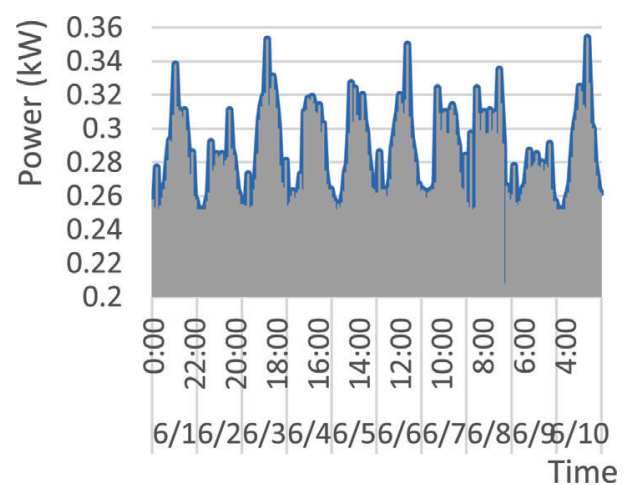

Figure 11 Power consumption of Micro BS5. 


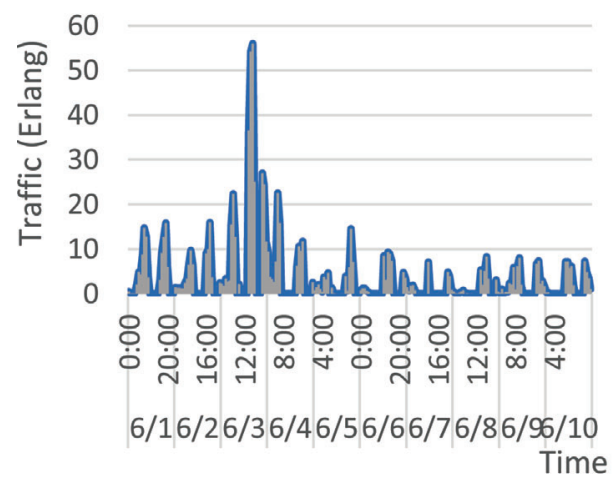

Figure 12 Traffic Volume of micro BS6.

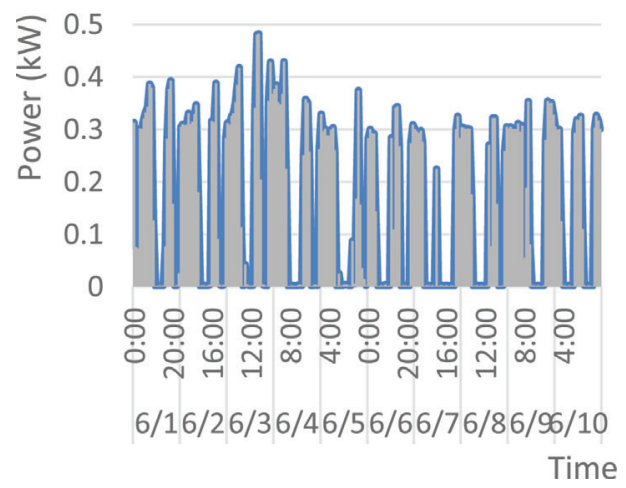

Figure 13 Power consumption of Micro BS6.

both urban and rural areas are lower. Likewise, in urban areas during peak hours (10:00 to 14:00 hrs.) and rural areas between 18:00 to 20:00 hours, the instantaneous BSs power consumption of both micro and macro BSs becomes higher due to random activities of the users.

The variations of time in the users' activities have an influence not only on the power consumption of the macro BSs, but also on the micro BSs power consumption. Hence, to cope up with the increased traffic load, additional hardware and processing resources will be needed, which will ultimately increase the overall power consumption of both the macro and micro BSs.

Figures 3, $5 \& 7$ (Macro BSs) and 9, $11 \& 13$ (Micro BSs) also show similar trends in changes in instantaneous power consumption pattern during high traffic load. In absolute values, higher instantaneous power consumptions 
of both macro and micro BSs are detected during the working days than during the weekend days (June 6-7, 2016). This is obviously because of the nature of the mobile telephony usage. The increased consumption during the working days is a result of higher traffic.

From the above figures, it can be clearly seen that the energy consumption fluctuates daily along the traffic loads. Although, it should be focused that when traffic load is low, energy consumption does not change, this indicates that the dynamic power management system based on traffic load is not available.

\subsection{Energy Efficiency Indicators}

An important parameter to determine the energy efficiency of a BS is area energy efficiency. In this study, heterogeneous BSs are compared so power consumption $\mathrm{PC}_{\text {area }}$ per covered area $\left(\mathrm{W} / \mathrm{m}^{2}\right)$ is defined to measure the power consumption and efficiency for different technologies. The energy efficiency of BSs is commonly defined as the instantaneous BSs power consumption $\left(\mathrm{P}_{\mathrm{el}}\right)$ needed to cover a certain area with radio signal (in $\left.\mathrm{W} / \mathrm{m}^{2}\right)$. The Power consumption $\mathrm{PC}_{\text {area }}$ per covered area is then defined as $[8,26]$.

$$
P C_{\text {area }}=\frac{P_{e l}}{\pi r^{2}}
$$

Where, $\mathrm{P}_{\mathrm{el}}$ is $\mathrm{BS}$ power consumption (Watt) and $\mathrm{R}$ is the range of $\mathrm{BS}$ coverage (meters). This parameter helps to compare the energy efficiency of different wireless technologies like 2G, 3G and 4G. For simplicity, it is assumed that each of the analyzed BSs has circular coverage area. Lower the $\mathrm{PC}_{\text {area }}$, the more energy-efficient is the BS. The antenna gain of the analyzed GSM $900 \mathrm{BS}$ is equal to $16 \mathrm{dBi}$, while for GSM $1800 \mathrm{BS}$ and UMTS $2100 \mathrm{BS}$, it is $18 \mathrm{dBi}$. The assessment of downlink coverage range for each of the BS is shown in Table 3. For the coverage computation, Okumura-Hate propagation model has been used for Macro BSs and Walkfish-Ikagemi propagation model for micro BSs [27].Based on these equations for a particular area, range of the coverage area is calculated, which is shown in Table 4 . The coverage range presented in Table 3 is calculated considering the operating transmit power of each of the BSs analysed. Since one particular area can be covered by many BSs with different frequency band, connection between power consumption and coverage in a heterogeneous network can be found as in Equation 2, which finally provides energy efficiency.

The minimum and maximum estimated area power consumption per BS and per single sector of analyzed BSs are shown in Table 4. It is noted that the macro BSs have higher total area power consumption as compared to the 
Table 3 Coverage range, transmit power and antenna Parameters

\begin{tabular}{lccccccc}
\hline BS Type & $\begin{array}{c}\text { Frequency } \\
(\mathrm{MHz})\end{array}$ & $\begin{array}{c}\text { Urban } \\
(\mathrm{km})\end{array}$ & $\begin{array}{c}\text { Suburban } \\
(\mathrm{km})\end{array}$ & $\begin{array}{c}\text { Rural } \\
(\mathrm{km})\end{array}$ & $\begin{array}{c}\text { Antenna } \\
\text { Height } \\
(\mathrm{m})\end{array}$ & $\begin{array}{c}\text { Antenna } \\
\text { Gain } \\
(\mathrm{dBi})\end{array}$ & $\begin{array}{c}\text { Transmit } \\
\text { Power } \\
(\mathrm{dBm} / \mathrm{W})\end{array}$ \\
\hline GSM micro & 900 & 0.26 & 1.06 & 3.38 & 8 & 16 & $41.14 / 13$ \\
GSM macro & 1800 & 0.19 & 0.49 & 1.66 & 20 & 18 & $47.8 / 60$ \\
UMTS macro & 2100 & 0.38 & 0.89 & 3.17 & 20 & 18 & $47.8 / 60$ \\
GSM micro & 1800 & 0.16 & 0.39 & 1.56 & 8 & 18 & $49 / 80$ \\
\hline
\end{tabular}

micro BSs, because of lower Transmit power and lower power consumption of micro BSs in comparison to macro BSs. This reveals that the micro base stations is useful for increasing capacity specially in urban areas. This approves the concept of installing micro BSs for increasing the capacity.

\subsection{Comparison of Energy Efficiency between Micro and Macro BSs}

The energy efficiency of macro BSs and micro BSs is analyzed by the electrical power to the coverage area of particular BS. For this, the power consumption data of both macro and micro BSs was measured for ten days, which is shown in Table 1. Table 4 shows the comparison of micro BSs and macro BSs in terms of power consumption per covered area. The coverage range transmit power and antenna parameters of micro BSs and macro BSs are shown in Table 3, which is calculated from the link budget [22, 28].

The power consumption per covered area of micro BSs is about 1.2 to 1.7 times higher than that of the macro BSs. The coverage range of a macro BS is 1.25 times higher than a micro BS due to its higher transmit power, antenna gain and antenna height which can be seen from Tables $3 \& 4$. As mentioned earlier, energy efficiency is inversely proportional to power consumption per covered area. So, a macro BS is more energy efficient than a micro BS in spite of its higher power consumption, which is similar to the result [8]. Therefore,

Table 4 Power Consumption per covered area for analysed BSs

\begin{tabular}{llccc}
\hline BS Type & Area & Coverage Range $(\mathrm{m})$ & $\mathrm{P}_{\mathrm{el}}(\mathrm{W})$ & $\mathrm{PC}_{\text {area }}(\mathrm{mW} / \mathrm{m} 2)$ \\
\hline \multirow{3}{*}{ GSM micro } & Urban & 160 & & 9.890 \\
& Suburban & 390 & 795 & 1.665 \\
& Rural & 1560 & & 0.104 \\
\hline \multirow{3}{*}{ GSM Macro } & Urban & 190 & & 13.498 \\
& Suburban & 490 & 1530 & 2.029 \\
& Rural & 1660 & & 0.177 \\
\hline
\end{tabular}




\section{Madhu Sudan Dahal et al.}

it can be concluded that a macro BS ensures coverage only and not suitable for quality service like high data rate and clear voice so it is not appropriate for rural areas. Micro BS, on the other hand, is suitable for dense urban areas, where there is high concentration of users and high data rates are required.

\subsection{Linear Regression Modelling}

For calculating the effects of the variable factor traffic load on the power consumption, regression models for each BS are developed. The developed regression models express power consumption of each BS as a function of traffic load given by Equation (2).

$$
\mathrm{Y}=\mathrm{A}+\mathrm{X} \beta
$$

Where

$\mathrm{Y}=$ instantaneous power consumption (dependent variable)

$\mathrm{A}=$ regression coefficient (constant term)

$\beta=$ weight of corresponding (coefficients)

$\mathrm{X}=$ independent variable (traffic load)

The linear regression model for each micro and macro BSs are plotted in Figures 14-19, which tend to fit the data value with $95 \%$ of confidence interval. For every analyzed BSs, separate linear regression models have been developed. The intercept values, linear model coefficients and overall power consumption equations are shown in Table 5, which presents the linear dependence of the power consumption on the traffic load. The instantaneous power consumption of every BS goes linearly with increased traffic load, which is can be seen in Figures 7-12. When the traffic is very low, the proposed linear models indicate static amount of power consumption. Likewise, when there is no traffic, the intercept value in the proposed models still ensures some static (residual) power consumption. It means that during no traffic period, certain amount of power consumption is always present for both, micro and

Table 5 Regression models with R-squared and adjusted R-squared value of analyzed BS types

\begin{tabular}{llcc}
\hline BS & R-Squared & Adjusted R Squared & Power Consumption y $(\mathrm{kW})$ \\
\hline BS 1 Macro & 0.7658 & 0.7648 & $\mathrm{y}=0.0017 * \mathrm{x}+1.2723$ \\
BS 2 Macro & 0.787 & 0.7861 & $\mathrm{y}=0.0015^{*} \mathrm{x}+1.2623$ \\
BS 3 Macro & 0.7931 & 0.7922 & $\mathrm{y}=0.0018^{*} \mathrm{x}+1.3709$ \\
BS 4 Micro & 0.2935 & 0.2905 & $\mathrm{y}=0.0119^{*} \mathrm{x}+0.1204$ \\
BS 5 Micro & 0.3151 & 0.3122 & $\mathrm{y}=0.0095 * \mathrm{x}+0.2320$ \\
BS 6 Micro & 0.4231 & 0.4207 & $\mathrm{y}=0.0054 * \mathrm{x}+0.2669$ \\
\hline
\end{tabular}


macro BSs. From Table 2, static BSs power consumption exceeds $1 \mathrm{~kW}$ for macro BSs, while in the case of micro BSs, it is less than $300 \mathrm{~W}$. This is due to high power amplifiers of macro BSs used for increasing transmitting power on levels, which are 3 to 6 times higher than those of micro BSs.

The R-squared statistics is used to test the accuracy of the developed linear regression models and to correlate the variables. The R-square value is a number that indicates how well a statistical model/regression line fits the real scattered data values. Table 5 shows the obtained R-squared values for both, macro and micro BSs, which illustrates that the R-squared value ranges from 0.7658 to 0.7922 for macro BSs and 0.2935 to 0.4231 for micro BSs. This indicates that the model explains good variability of the response data around its mean for macro BSs, but for micro BSs, the model has somewhat inferior variability of the response data around its mean. Another parameter used in the analysis is adjusted-squared parameter. The adjusted R-squared is a modified version of R-squared, which is adjusted for the number of predictors in the model. The adjusted R-squared can be negative and it is always lower than the R-squared parameter. Table 5 shows that the calculated adjusted R-square values range from 0.7648 to 0.7922 for macro BSs and 0.2905 to 0.4207 for micro BSs. Obtained result for adjusted R- squared values are almost equal to those of R-squared, indicating similar precision pattern due to correlation with R-squared values. Hence, the developed regression models could be very useful to forecast the required power level in order to cope up with the constantly increasing traffic demand.

\subsection{Comparison of Regression Models between Micro and Macro BSs}

The energy efficiency of micro and macro base stations installed in rural and urban areas is investigated for different traffic patterns. The power consumption accumulated over ten days for both micro and macro base station is as in Equation 2. The relationship between the power consumption and traffic load of each base station is shown in Table 5 and Figures 14-19. Through the meticulous measurement of real power consumption against traffic load for 10 consecutive days, regression models have been developed. Based on the model, energy efficiency of micro and macro BSs have been compared by power consumption and coverage range. Figures 14-16 show the regression models of three macro BSs and Figures 17-19 show the regression models of three micro BSs. As traffic increases, the power consumption also increases, which show a linear relationship between power consumption and traffic for 


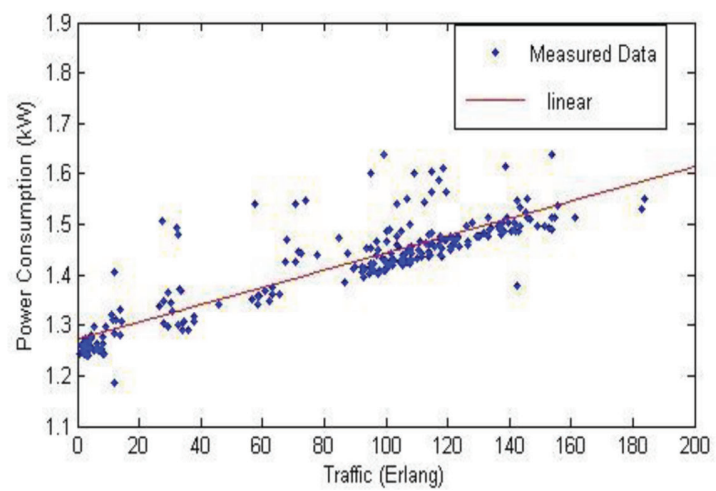

Figure 14 Regression Model of macro BS1BS Antenna.

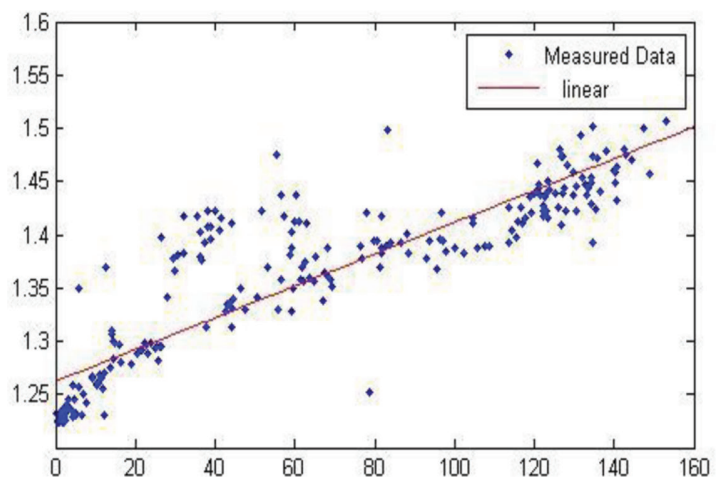

Figure 15 Regression Model of Macro BS2.

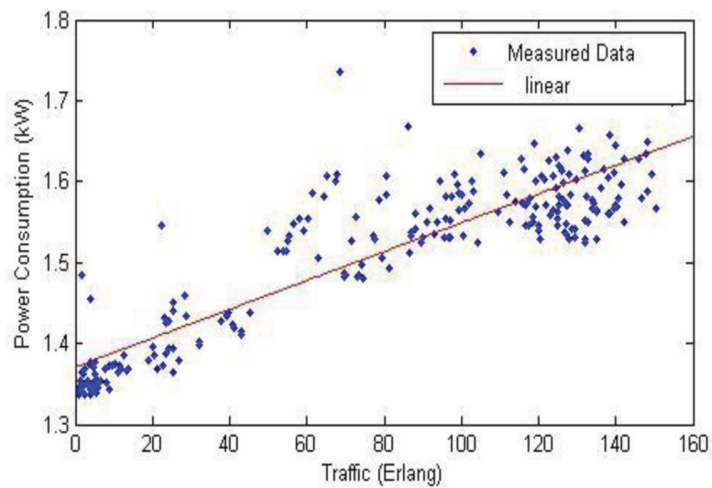

Figure 16 Regression Model of Macro BS3. 


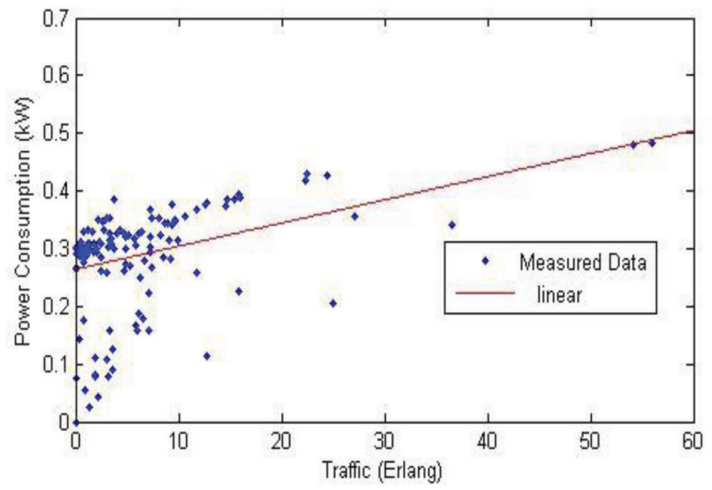

Figure 17 Regression Model of Micro BS4.

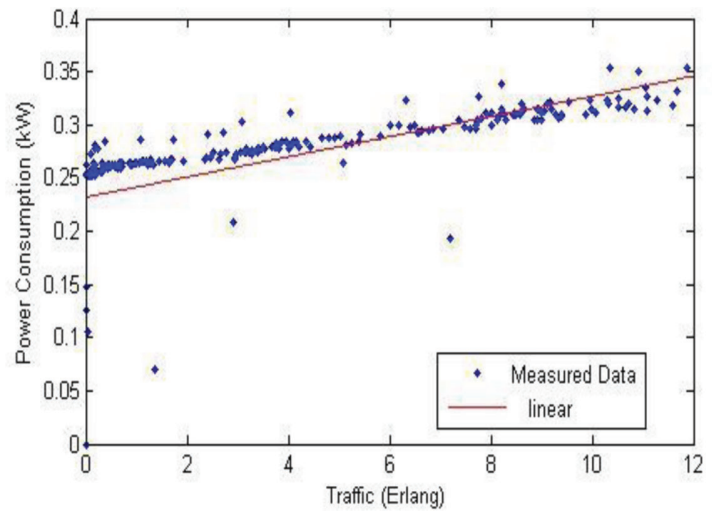

Figure 18 Regression Model of Micro BS5.

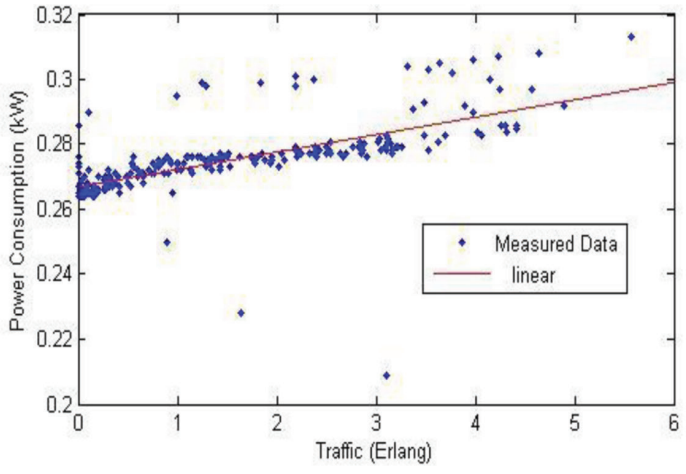

Figure 19 Regression Model of Micro BS6. 


\section{Madhu Sudan Dahal et al.}

both micro and macro base stations. But during low traffic, the linear model does not show the linear relationship. This indicates that the developed models fit only during high traffic. As seen from Table 5, the developed models have two components; one is static which is not dependent on the traffic load and the other depends on traffic load. Since micro base stations have low traffic as compared with macro base stations, the impact of traffic for micro base stations is low as compared with that of macro base stations. The impact of the traffic variations on the power consumption is different for micro and macro base stations.

\section{Conclusion}

This research shows the difference in behavior of power consumption of micro and macro BSs based on the real traffic generated on cellular communication. The micro and macro BSs are compared through regression modeling and energy efficiency. The power consumption of micro and macro base stations is investigated based on the traffic load. Energy and traffic measurements were carried out for ten consecutive days on six base stations located in urban and rural area.

The results confirmed that there is a direct correlation between instantaneous power consumption and traffic load during high traffic. However, power consumption is almost the same during low traffic. The traffic load of a macro BS is 4 times higher than that of a micro BS, therefore the developed regression models fit well for macro BS as compared to micro BS. The developed regression models also showed that the traffic variations for micro and macro BSs have different impact on the area and instantaneous power consumption.

It was found that the macro BSs consume about 2 times more power than the micro BSs. Because of higher energy efficiency, macro BSs are suitable only for the purpose of coverage whereas micro BSs are appropriate for a wide range of users, which requires high data rates. In the future, the algorithm for dynamic Transmitter shutdown during low traffic load should be developed, which will increase the energy efficiency of wireless network.

\section{Acknowledgements}

The authors are grateful to all the colleagues for their valuable support and for being a part of the discussion. Only the corresponding author is responsible for any errors remaining in this paper. 


\section{References}

[1] Gautam, D. K. (2016). NTC and Ncell: Telecommunication and Strategies. South Asian Journal of Business and Management Cases, 5(1), 126-133.

[2] Union IT. (2012). Impact of Broadband of the Economy.

[3] Authority NE. Nepal Electricity Authority 2016. Available at: http://nea.org.np/loadshedding.html

[4] Dahal M. S., Khadka S. K., Shakya S. R., and Shrestha J. N. (2015). A Regression Model and R2-Statistics Analysis of Base Stations Power Consumption under Real Traffic Loads. Proceeding IOE Grad. Conf. $1-6$.

[5] Dahal, M. S., Shrestha, J. N., and Shakya S. R. (2016). Power Consumption Modeling of Base Station as per Traffic. South Am. J. Acad. Res.

[6] Dahal, M. S., Khadka S. K., Shrestha J. N., Shakya S. R. (2015). A Regression Analysis for Base Station Power Consumption under Real Traffic Loads - A Case of Nepal. Am. J. Eng. Res. 4, 85-90.

[7] Spagnuolo, A., Petraglia, A., Vetromile, C., Formosi, R., and Lubritto, C. (2015). Monitoring and optimization of energy consumption of base transceiver stations. Energy, 81, 286-293. doi: 10.1016/j.energy.2014.12.040

[8] Deruyck, M., Tanghe, E., Joseph, W., and Martens, L. (2011). Modelling and optimization of power consumption in wireless access networks. Computer Communications, 34(17), 2036-2046. doi: 10.1016/j.comcom.2011.03.008

[9] Domenico A De, Petersson S. Earth. 2012.

[10] Deruyck, M., Tanghe, E., Joseph, W., and Martens, L. (2011). "Modelling the energy efficiency of microcell base stations". In 1st International Conference on Smart Grids, Green Communications and IT Energy-Aware Technologies (ENERGY-2011), IARIA. 1-6.

[11] Gati, A., Martinez-Lopez, S., and En-Najjary, T. (2014). Impact of traffic growth on energy consumption of LTE networks between 2010 and 2020. In Wireless Communications and Networking Conference Workshops (WCNCW), 2014 IEEE, 150-154. doi: 10.1109/WCNCW.2014.6934877

[12] Nahas, M., Ghantous, M., Ismail, KHAN., and Assaf, B. (2014). For Better Energy Consumption and Management in Future Cellular Networks. In 2nd International Conference on Renewable Energy for Developing Countries, REDEC-2014, Lebanon: IEEE. 
[13] Ge, X., Yang, J., Gharavi, H., and Sun, Y. (2017). Energy efficiency challenges of $5 \mathrm{G}$ small cell networks. IEEE Communications Magazine, 55(5), 184-191. doi: 10.1109/MCOM.2017.1600788

[14] Liu, C., Natarajan, B., and Xia, H. (2016). Small cell base station sleep strategies for energy efficiency. IEEE Transactions on Vehicular Technology, 65(3), 1652-1661. doi: 10.1109/TVT.2015.2413382

[15] Chen, S., Qin, F., Hu, B., Li, X., and Chen, Z. (2016). User-centric ultra-dense networks for 5G: challenges, methodologies, and directions. IEEE Wireless Communications, 23(2), 78-85. doi: 10.1109/MWC.2016.7462488

[16] Deruyck, M., Joseph, W., and Martens, L. (2014). Power consumption model for macrocell and microcell base stations. Transactions on Emerging Telecommunications Technologies, 25(3), 320-333. doi: 10.1002/ett. 2565

[17] Deruyck, M., Tanghe, E., Joseph, W., and Martens, L. (2012). Characterization and optimization of the power consumption in wireless access networks by taking daily traffic variations into account. EURASIP Journal on Wireless Communications and Networking, 2012(1), 248. doi: 10.1186/1687-1499-2012-248

[18] Arnold, O., Richter, F., Fettweis, G., and Blume, O. (2010). Power consumption modeling of different base station types in heterogeneous cellular networks. In Future Network and Mobile Summit, 1-8. IEEE.

[19] Peng, C., Lee, S. B., Lu, S., Luo, H., and Li, H. (2011). Traffic-driven power saving in operational 3G cellular networks. In Proceedings of the 17th Annual International Conference on Mobile Computing and Networking, 121-132. ACM. doi: 10.1145/2030613.2030628

[20] Ayang, A., Ngohe-Ekam, P. S., Videme, B., and Temga, J. (2016). Power Consumption: Base Stations of Telecommunication in Sahel Zone of Cameroon: Typology Based on the Power Consumption-Model and Energy Savings. Journal of Energy, 2016. doi: 10.1155/2016/3161060

[21] Prithiviraj, V., Venkatraman, S. B., and Vijayasarathi, R. (2013). Cell zooming for energy efficient wireless cellular network. Journal of Green engineering, 3(4), 421-434. doi: 10.13052/jge1904-4720.344

[22] Huawei Technologies. BTS Product Description. Shenzhen: 2009.

[23] CBS. Central Bureau of Statistics. Cent Bur Stat 2016. www.cbs.gov.np.

[24] Nepal Telecommunication Authority. Management Information System (MIS) report. 2016. 
[25] Blume, O., Eckhardt, H., Klein, S., Kuehn, E., and Wajda, W. M. (2010). Energy savings in mobile networks based on adaptation to traffic statistics. Bell Labs Technical Journal, 15(2), 77-94. doi: 10.1002/bltj.20442

[26] Deruyck, M., Tanghe, E., Joseph, W., Vereecken, W., Pickavet, M., Dhoedt, B., and Martens, L. (2010). Towards a deployment tool for wireless access networks with minimal power consumption. In IEEE 21st International Symposium on Personal, Indoor and Mobile Radio Communications Workshops (PIMRC Workshops), 295-300. IEEE.

[27] Rappaport TS. Wireless communications: principles and practice. Prentice Hall PTR; 1996.

[28] Huawei Technologies. RRU Description. 2012.

\section{Biographies}

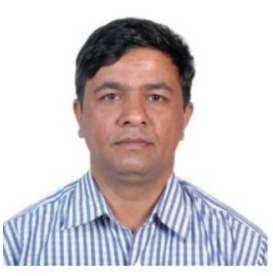

Madhu Sudan Dahal is a Ph.D student at the Institute of Engineering, Tribhuvan University since 2013. He attended the Tribhuvan University, Nepal where he received his B.E. in electronics and communication engineering in 2006 and M.Sc. in Renewable Energy Engineering from the Institute of Engineering (IOE) in 2010. Currently he is working in Nepal Telecom as a senior engineer since 2008. He, as a Telecommunication expert and professional, has acquired a solid experience in service quality management of Telecommunication networks. He is also a visiting faculty member. He is currently completing a doctorate in green cellular communication at the department of Mechanical, Institute of Engineering, Trihbuvan University. His Ph.D work centers on green telecommunication and discusses the green networking movement to develop new energy efficient and green solutions. 


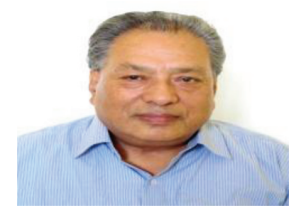

Jagan Nath Shrestha is currently visiting Professor at Center for Energy Studies, Institute of Engineering, Tribhuvan University, Nepal. He obtained Ph.D. (Physics/Solar Energy) from L.N.M. University, India in April 2006, Master's Degree in Educational Technology and Media Studies, Hull University, UK in 1986 and Master of Science in Engineering (Radio Communication), from Moscow Institute of Telecommunications in 1972. He was a member of Board of Directors at Nepal Telecommunication Corporation during the period of 1985-1988.

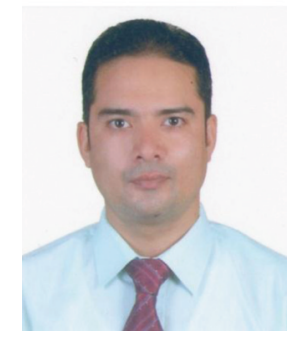

Shree Raj Shakya has his Doctoral Degree in Energy from Asian Institute of Technology, Thailand and Masters Degree in Renewable Energy Engineering from Tribhuvan University (TU), Nepal. Currently, Dr. Shakya is Acting Director of Centre for Energy Studies, Institute of Engineering, Tribhuvan University (IOE/TU). He is also the Program Coordinator of M.Sc. Engineering in Energy Systems Planning and Management (MSESPM) program under Institute of Engineering, TU. His main expertise is renewable energy technology, energy economics, energy and climate change policy modelling and sustainable energy development. 